\title{
Impact of In Situ Stress Distribution Characteristics on Jointed Surrounding Rock Mass Stability of an Underground Cavern near a Hillslope Surface
}

\author{
Bangxiang Li, ${ }^{1}$ Yong Li, ${ }^{1,2}$ Weishen Zhu, ${ }^{1}$ Chao Li, ${ }^{1}$ and Zhenxing Dong1 \\ ${ }^{1}$ Geotechnical \& Structural Engineering Research Center, Shandong University, Jinan, Shandong Province 250061, China \\ ${ }^{2}$ School of Civil Engineering, Shandong University, Jinan, Shandong Province 250061, China \\ Correspondence should be addressed to Yong Li; yongli@sdu.edu.cn
}

Received 20 October 2016; Accepted 9 January 2017; Published 29 January 2017

Academic Editor: Vadim V. Silberschmidt

Copyright (C) 2017 Bangxiang Li et al. This is an open access article distributed under the Creative Commons Attribution License, which permits unrestricted use, distribution, and reproduction in any medium, provided the original work is properly cited.

In this paper, a series of numerical simulations are performed to analyze the in situ stress distribution characteristics of the rock mass near different slope angles hillslope surfaces, which are subjected to the vertical gravity stress and different horizontal lateral stresses and the influence which the in situ stress distribution characteristics of $45^{\circ}$ hillslope to the integral stability of surrounding rock mass when an underground cavern is excavated considering three different horizontal distances from the underground cavern to the slope surface. It can be concluded from the numerical results that different slope angles and horizontal lateral stresses have a strong impact on the in situ stress distribution and the integral surrounding rock mass stability of the underground cavern when the horizontal distance from the underground cavern to the slope surface is approximately $100 \mathrm{~m}$ to $200 \mathrm{~m}$. The relevant results would provide some important constructive suggestions to the engineering site selection and optimization of large-scale underground caverns in hydropower stations.

\section{Introduction}

China is a mountainous country, especially in its southwestern areas. With the implementation of Western Development Strategy proposed by the Chinese government, a large number of underground caverns, tunnels, and openings are being and will be constructed in mountain areas [1]. These projects are always located in high mountains and deep-incised valleys. The Chinese western area, especially the Tibetan regions, is subject to the continuous extrusion of the India plate. As a result, the altitude of Qinghai-Tibet Plateau is continuously rising over millions of years, and the alpine canyon tomography has been formed in these areas [2, 3]. The modern crustal movement and tectonic activities result in the complicated geological conditions and high in situ stress field [4]. Therefore, it is greatly difficult to perform the engineering project design and constructions in these areas [5-8]. In general, the selected locations for the underground caverns in hydropower stations are often close to the toe areas of slopes, and the horizontal distance from the underground caverns to the slope surface is always within $400 \mathrm{~m}$. In this area from the underground caverns to the slope surface, the in situ stress field is significantly influenced by the complicated geological conditions [9]. Accordingly, it is necessary to make a full understanding of the distribution principles of initial in situ stress field before large-scale engineering site selections in mountain areas.

For the time being, the studies on the underground projects in mountain areas mainly focus on two major aspects: one is the distribution of initial in situ stress, and the other is the excavation stability of large-scale underground caverns [10]. A large number of experiences confirm that the local terrain and slope angles have a great influence on the distribution characteristics of initial in situ stress field in the mountains. McTigue and Mei [11] reported that the terrains had an obvious impact on the initial in situ stress field, even though the slope gradient was only $10 \%$. At present, to carry out the field measurement of the initial in situ stress is still the most effective approach to make good understandings of the in situ stress field. A number of previous scholars 
proposed that the initial in situ stress field can be predicted according to limited in situ stress measured values and numerical approaches, which included the in situ stress regression method $[12,13]$, stress or displacement function method [14], boundary load or displacement adjustment method [15], and orthogonal experiment method [16]. As for the deep-incised valley areas, the development and evolution of the valley is also a significant factor to affect the initial in situ stress field. For this reason, some scholars proposed a few numerical methods to analyze the initial in situ stress field [17]. Although local distribution characteristics of initial in situ stress can be reflected by limited field measuring values, the global understanding of the initial in situ stress field cannot be achieved through a large number of field monitoring works owing to the limitations in the site topography, high cost, testing technology, and so on [18]. Therefore, in the conventional numerical simulations, the direct embedded depth of the upper rock mass is regarded as the basis for calculating the vertical initial in situ stress, namely, $\sigma_{y}=\gamma h$ (here, $\sigma_{y}$ represents the vertical initial in situ stress; $\gamma$ is the density of rock mass; $h$ is the direct embedded depth of upper rock mass). Obviously, the conventional numerical simulations ignore the effects of the slope gradient, local tomography, and horizontal in situ stress, which leads to great errors existing in the numerical results. Yu et al. [19] studied the influences of initial in situ stress on the stability of underground project under the conditions of different slope angles, but the influence of horizontal in situ stress was not considered and the rock mass was regarded to be intact in this study. In this paper, the distribution characteristics of initial in situ stress have been investigated considering different slope angles and different horizontal in situ stresses. Furthermore, numerical investigations on the integral stability of surrounding rock mass have been conducted considering different horizontal distances from the underground cavern to the slope surface.

\section{In Situ Stress Distribution under Different Slope Angles}

Before manual excavations, the original stress that existed in the natural rock mass is defined as in situ stress. The cause of in situ stress formation is quite complicated, which is generally regarded as the development results of rock mass gravity and tectonic movement of the earth plate $[20,21]$. In the meantime, the in situ stress field is also greatly influenced by various environmental factors, such as lithology, terrain, topography, fault, and joint [22]. In practical underground projects, the in situ stress measurements and the inverse calculation for in situ stress field can be performed in quite a few big projects $[23,24]$. However, the number of measuring points is quite limited, and consequently the back analysis results for the in situ stress field are not perfectly accurate [25, 26]. For a general project, the in situ stress measurement work may not be carried out owing to a limited investment, and in situ stress field can be estimated according to the overburden depth and mountain features. As far as it is concerned, the most frequently used method is using the direct overburden depth to calculate the vertical in situ stress, and it can be
TABLE 1: Physicomechanical parameters of a typical rock mass.

\begin{tabular}{lcc}
\hline $\begin{array}{l}\text { Natural density } \\
\left(\mathrm{g} / \mathrm{cm}^{3}\right)\end{array}$ & $\begin{array}{c}\text { Young's modulus } \\
(\mathrm{GPa})\end{array}$ & Poisson's ratio \\
\hline 2,610 & 18 & 0.21 \\
\hline
\end{tabular}

guaranteed to bring significant errors. In this paper, the in situ stress calculation results using this method are compared with numerical simulation results using FLAC3D.

In the numerical simulations, FLAC3D is employed to perform a numerical analysis on the in situ stress distribution characteristics of the rock mass near a hillslope surface, which is subjected to the vertical gravity stress and the horizontal lateral stress. The numerical model is a plane strain model, and the typical elastoplastic constitutive model, Mohr-Coulomb criterion, is adopted in the numerical calculations. The five boundary planes of front, rear, left, right, and bottom are subject to unilateral constraints. Three typical slope angles $\left(30^{\circ}, 45^{\circ}\right.$, and $\left.60^{\circ}\right)$ are selected in the numerical simulations. Figure 1 shows the numerical model with a slope angle of $45^{\circ}$ and three schemes to locate an underground cavern under different slope angles. Table 1 shows the physicomechanical parameters of a typical rock mass. In order to investigate the values and distribution principles of vertical in situ stress and the maximum principal stress, here, we define two parameters $N_{1}$ and $N_{2}$ to quantitatively evaluate the differences between the numerically calculated in situ stress and the product of the rock mass density and the overburden depth:

$$
\begin{aligned}
& N_{1}=\frac{\sigma_{\max }}{\gamma h} \\
& N_{2}=\frac{\sigma_{y y}}{\gamma h},
\end{aligned}
$$

where $\sigma_{y y}$ is the vertical in situ stress obtained by numerical simulations; $\sigma_{\max }$ is the maximum in situ stress; $\gamma$ denotes the rock mass density; $h$ denotes the overburden depth.

\subsection{In Situ Stress Distribution without Considering Horizontal} Tectonic Stress. In this part, the self-weight stress is only considered in the numerical simulations, which have been performed under three different slope angles of $30^{\circ}, 45^{\circ}$, and $60^{\circ}$, respectively. The numerical stress values at the vertical coordinate of $0 \mathrm{~m}$ are selected to make a sufficient analysis. Figures 2 and 3 show the changes of $N_{1}$ and $N_{2}$ at the vertical coordinate of $0 \mathrm{~m}$. It is obvious that the values of $N_{1}$ and $\mathrm{N}_{2}$ change dramatically when the horizontal coordinate is from $0 \mathrm{~m}$ to $100 \mathrm{~m}$. Owing to the local stress concentration, the maximum $N_{1}$ is approximately 16 and the maximum $N_{2}$ is approximately 10 near the slope toe. This shows the numerically calculated in situ stress values are more than ten times larger than the values of $\gamma h$ at the largest. The area where the horizontal coordinate is from $100 \mathrm{~m}$ to $200 \mathrm{~m}$ can be defined as a stress transition zone. When the horizontal coordinate is over $200 \mathrm{~m}$, the values of $N_{1}$ and $N_{2}$ get closer to one, which show that the in situ stress of this area is almost not influenced by the slope surface. 


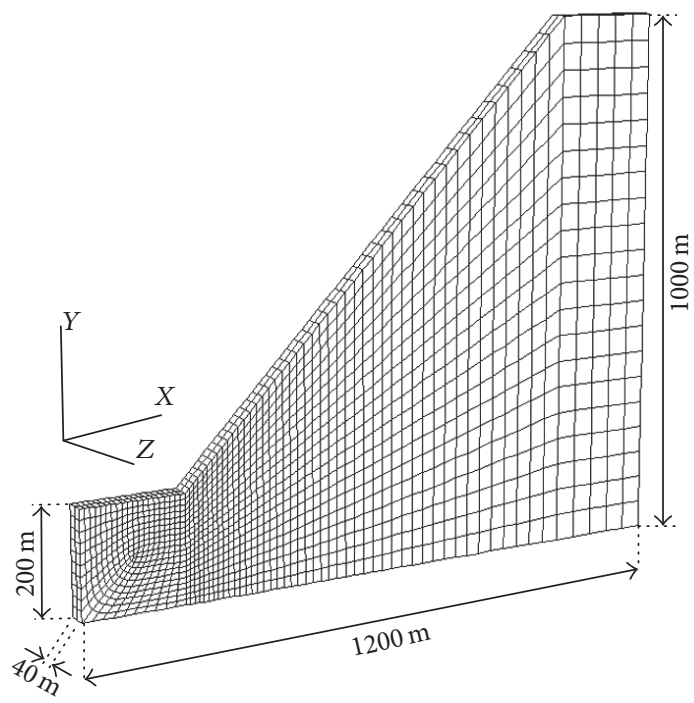

(a)

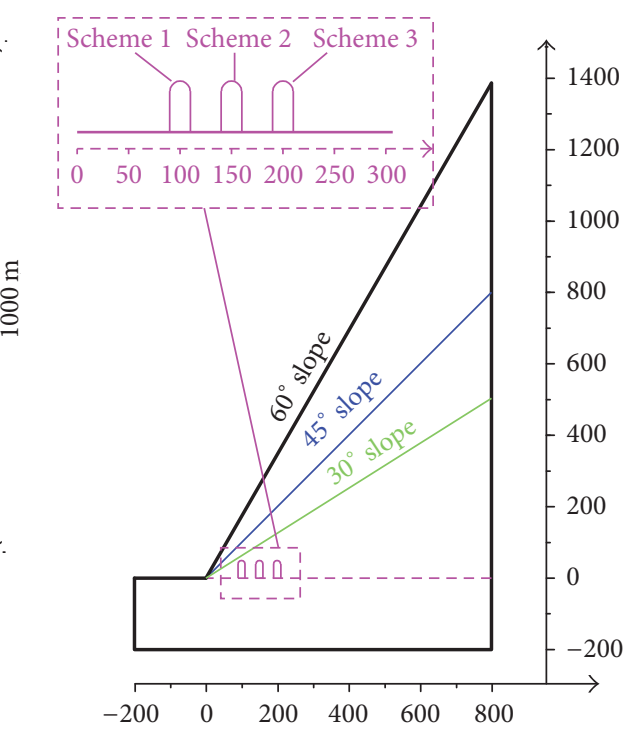

(b) (Unit: $\mathrm{m}$ )

FIGURE 1: A numerical model and three schemes: (a) a slope angle of $45^{\circ}$; (b) three schemes to locate an underground cavern under different slope angles.

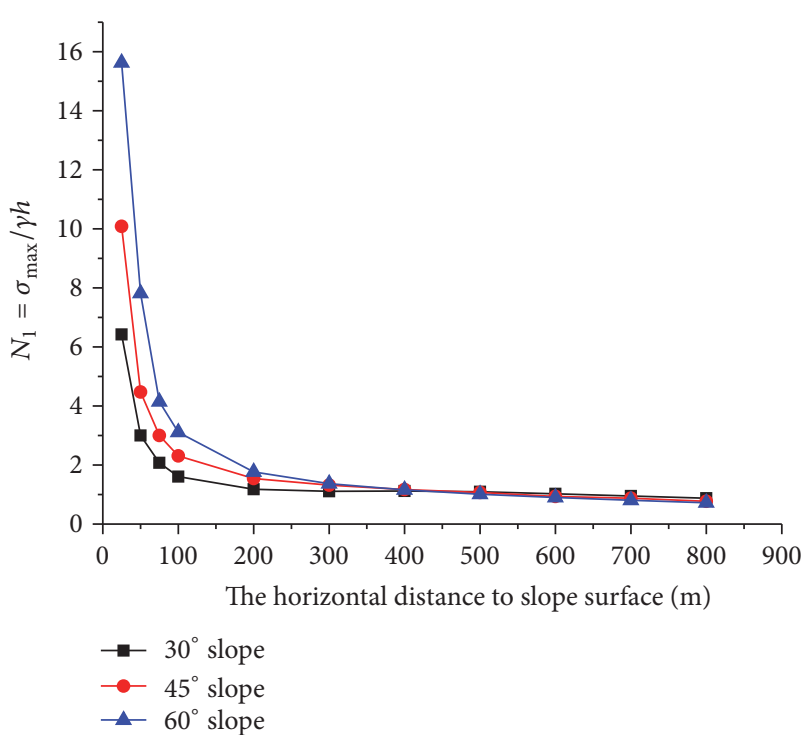

Figure 2: Variation curves of $N_{1}$ at the elevation of $0 \mathrm{~m}$ in different slope angles only considering the gravity stress.

Then the in situ stress distribution characteristics at the vertical coordinate of $100 \mathrm{~m}$ have been also numerically simulated and analyzed. Since the variation principles of $N_{1}$ and $N_{2}$ are almost similar, here the variation curve of $N_{1}$ is only presented in Figure 4 . It shows that the in situ stress distribution characteristics have similar laws with those where the vertical coordinate is one. The maximum values of $N_{1}$ and $N_{2}$ are 10 and 8 , the area where the horizontal coordinate is from $100 \mathrm{~m}$ and $200 \mathrm{~m}$ is still the stress transition area, and the values of $N_{1}$ and $N_{2}$ approach one when the horizontal coordinate is over $200 \mathrm{~m}$.

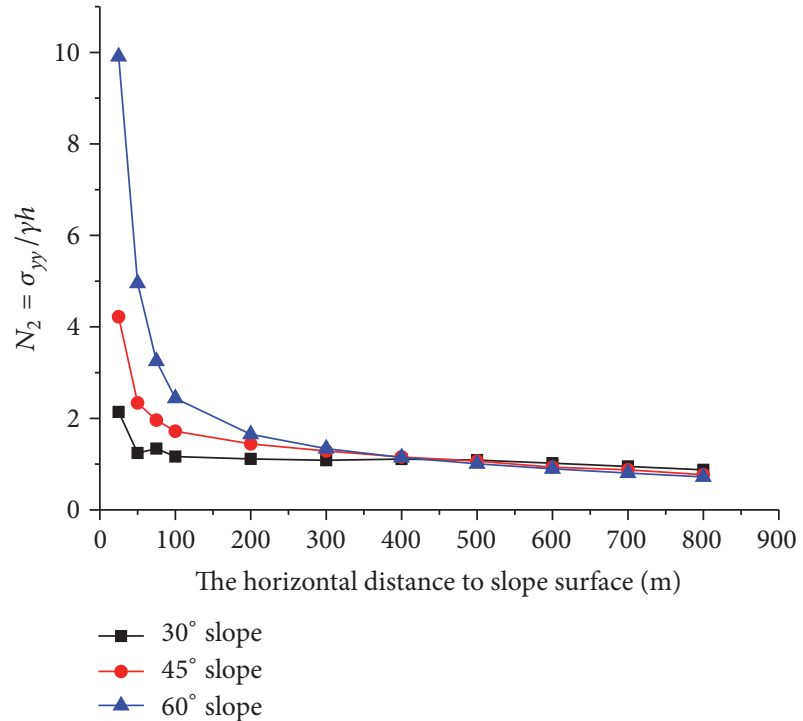

FIgURE 3: Variation curves of $N_{2}$ at the elevation of $0 \mathrm{~m}$ in different slope angles only considering the gravity stress.

In the mountain slope, the in situ stress values near the slope surface are generally considered to be quite small as the overburden depths are relatively shallow. However, the in situ stress values obtained by numerical simulations show a vastly different distribution principle as shown in Figure 5. On the horizontal plane of the same elevation, the maximum principal stresses increase at first and then decrease with the increment of the horizontal coordinate. In other words, the in situ stress of the area within a certain distance to the slope surface exhibits a higher value owing to the mountain slope effect, and this effect would become increasingly evident with 


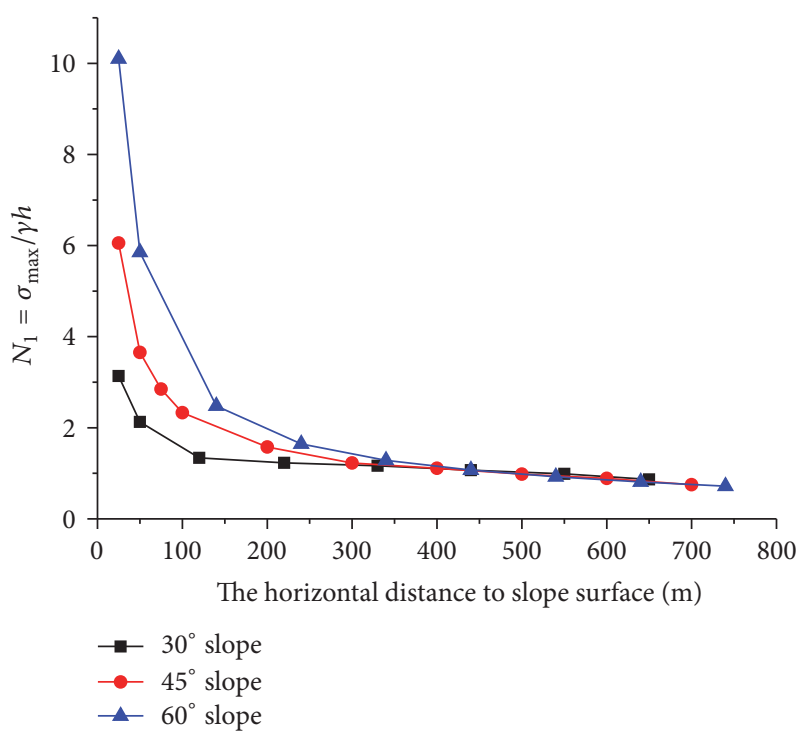

Figure 4: Variation curves of $N_{1}$ at the elevation of $100 \mathrm{~m}$ in different slope angles only considering the gravity stress.

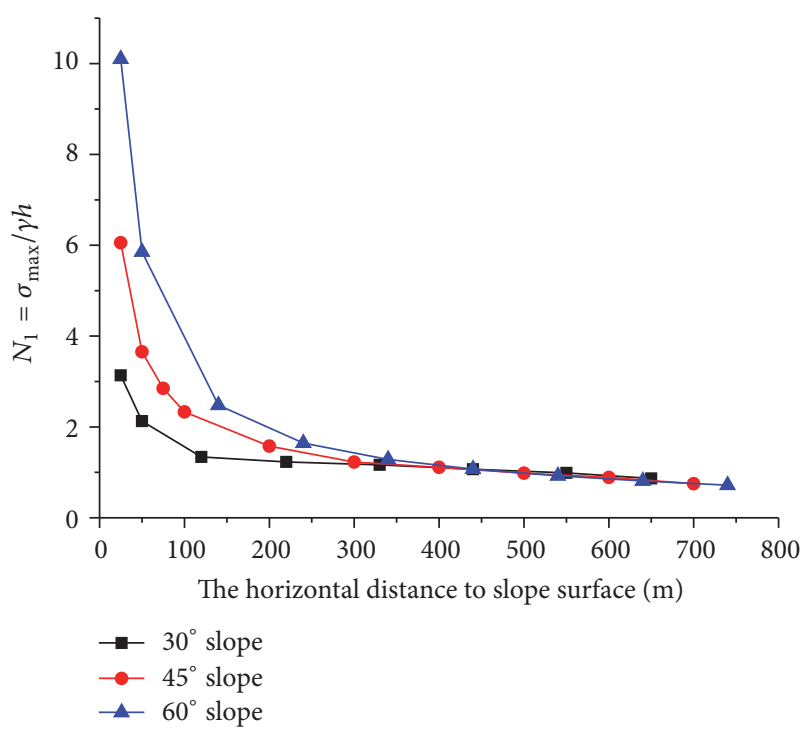

FIGURE 5: Variation curves of the maximum principal stress at the elevation of $100 \mathrm{~m}$ in different slope angles only considering the gravity stress.

the increment of the slope angle. In particular, when the slope angle is equal to $60^{\circ}$, the calculated maximum principal stress is up to $17.5 \mathrm{MPa}$, which is more than ten times of the values of $\gamma h$.

\subsection{In Situ Stress Distribution considering Horizontal Tectonic} Stress. Generally speaking, the horizontal tectonic stress cannot be neglected in numerical simulation. The horizontal tectonic stresses are usually applied on the numerical model based on considering different lateral pressure coefficients $\left(k_{0}\right)$. According to the engineering experiences from numerous similar large-scale underground caverns in hydropower stations in China [27], the lateral pressure coefficient is

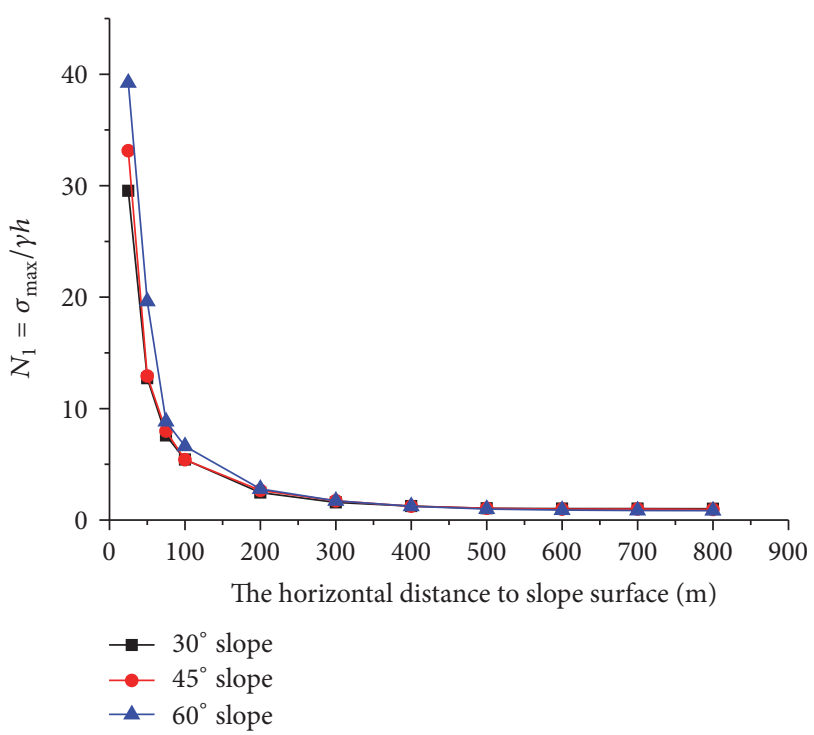

FIGURE 6: Variation curves of $N_{1}$ at the elevation of $0 \mathrm{~m}$ in different slope angles when the lateral pressure coefficient is equal to 1.5 .

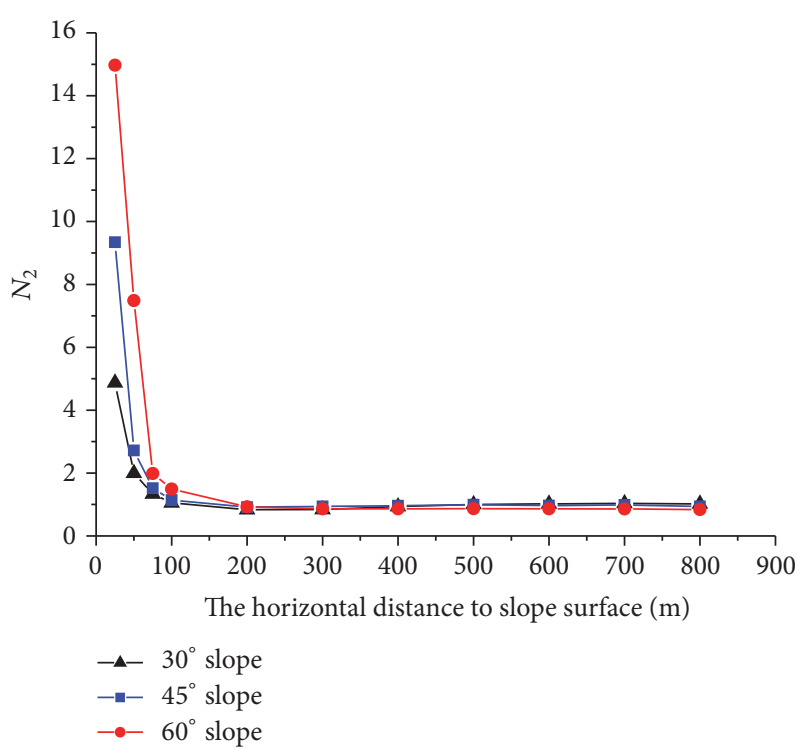

FIGURE 7: Variation curves of $N_{2}$ at the elevation of $0 \mathrm{~m}$ in different slope angles when the lateral pressure coefficient is equal to 1.5.

usually determined as $k_{0}=1.5$. Therefore, the in situ stress distribution at the vertical elevation of $0 \mathrm{~m}$ has been analyzed. The variations of $N_{1}$ and $N_{2}$ are quite similar as shown in Figures 6 and 7. From these curves, under the influences of both the gravity and horizontal tectonic stress, the values of $N_{1}$ and $N_{2}$ change dramatically when the horizontal coordinate is from $0 \mathrm{~m}$ to $100 \mathrm{~m}$. Owing to the local stress concentration, the maximum $N_{1}$ is approximately 40 and the maximum $N_{2}$ is approximately 16 near the slope toe. The area where the horizontal coordinate is from $100 \mathrm{~m}$ to $200 \mathrm{~m}$ is still the stress transition area, and the values of $N_{1}$ and $N_{2}$ approach one when the horizontal coordinate is over $200 \mathrm{~m}$. 


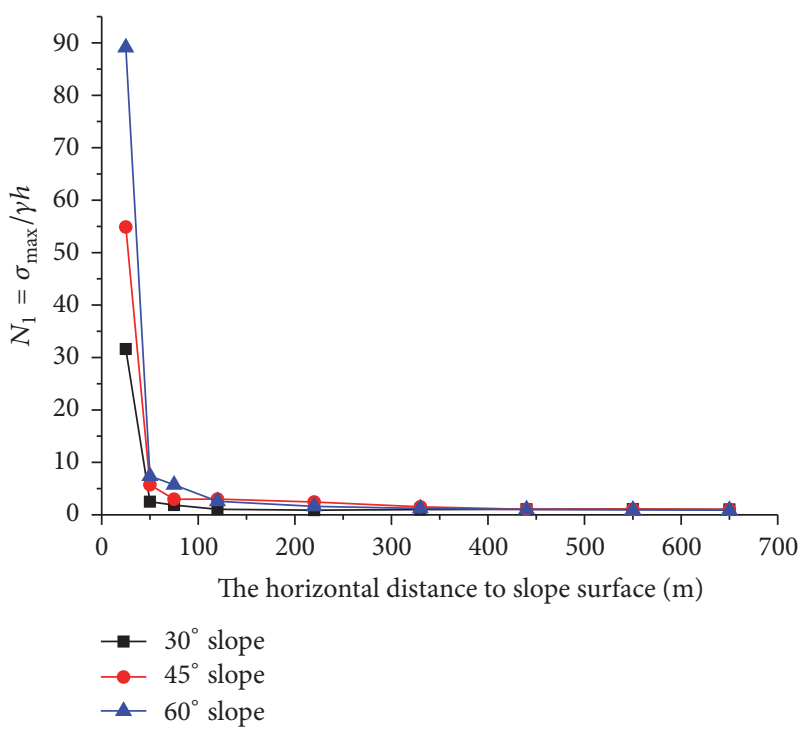

FIGURE 8: Variation curves of $N_{1}$ at the elevation of $100 \mathrm{~m}$ in different slope angles when the lateral pressure coefficient is equal to 1.5 .

Likewise, the in situ stress distribution at the vertical elevation of $100 \mathrm{~m}$ has also been analyzed and the variation curves of $N_{1}$ are shown in Figure 8. It can be found that the dramatic changes of $N_{1}$ and $N_{2}$ exhibit from $0 \mathrm{~m}$ to $50 \mathrm{~m}$. Owing to the local stress concentration, the maximum $N_{1}$ is approximately 90 and the maximum $N_{2}$ is approximately 55 near the slope toe. The area where the horizontal coordinate is from $50 \mathrm{~m}$ to $200 \mathrm{~m}$ is the stress transition area, and the values of $N_{1}$ and $N_{2}$ approach one when the horizontal coordinate is over $200 \mathrm{~m}$.

From the above analysis of different schemes, owing to the stress concentration and the slope surface effect, the values of $N_{1}$ and $N_{2}$ are becoming larger, and this principle behaves most prominent at the slope angle of $60^{\circ}$. The more the lateral pressure coefficients increase, the greater the in situ stresses near the slope surface become.

\section{In Situ Stress Distribution in an Actual Engineering Project}

In order to validate the in situ stress distribution principle near the slope surface, the Ertan hydropower station is taken as an actual engineering project. This project is located in the lower reaches of the Yalong River in the city of Panzhihua, Sichuan Province, China. It is a typical hydropower station with an installed capacity of 3.3 million $\mathrm{kW}$. The underground caverns on both banks are deeply buried in the massif. The overburden depths of the caverns are from $100 \mathrm{~m}$ to $240 \mathrm{~m}$. The host rock near the underground caverns is composed of pegmatite, Permian basalt, and metamorphic basalt. In situ stress measurements data show that the underground caverns are located in an anisotropic and high in situ stress field. The surrounding rock mass stability is greatly influenced by the joint effect of the gravity and the horizontal tectonic stress, and the horizontal tectonic stress is the dominant factor.
TABle 2: Physicomechanical parameters of the surrounding rock mass and four weathering zones.

\begin{tabular}{lccc}
\hline $\begin{array}{l}\text { Classifications } \\
\text { of rock mass }\end{array}$ & $\begin{array}{c}\text { Natural density } \\
\left(\mathrm{g} / \mathrm{cm}^{3}\right)\end{array}$ & $\begin{array}{c}\text { Young's modulus } \\
(\mathrm{GPa})\end{array}$ & $\begin{array}{c}\text { Poisson's } \\
\text { ratio }\end{array}$ \\
\hline $\begin{array}{l}\text { Intact rock mass } \\
\begin{array}{l}\text { Weathering } \\
\text { layer number 1 }\end{array}\end{array}$ & 2,610 & 40 & 0.20 \\
$\begin{array}{l}\text { Weathering } \\
\text { layer number 2 }\end{array}$ & 2,160 & 32 & 0.21 \\
$\begin{array}{l}\text { Weathering } \\
\text { layer number 3 }\end{array}$ & 1,935 & 16 & 0.22 \\
$\begin{array}{l}\text { Weathering } \\
\text { layer number } 4\end{array}$ & 1,710 & 8 & 0.23 \\
\hline
\end{tabular}

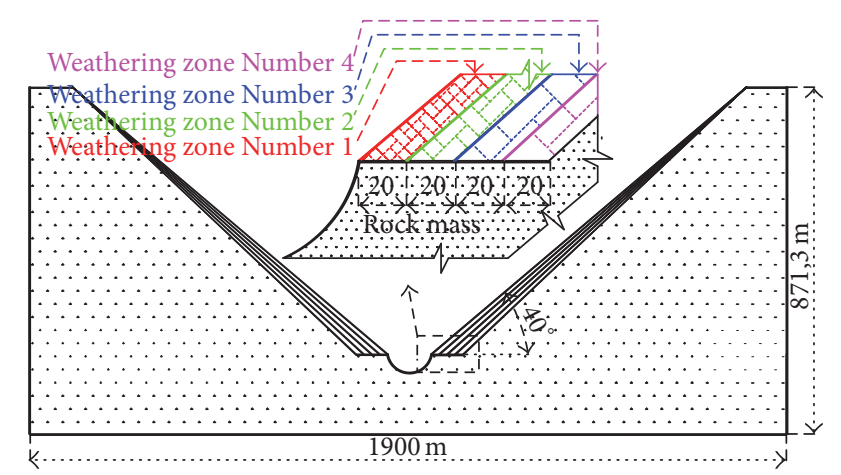

FIGURE 9: The planar graph of the mountain in the Ertan hydropower station.

The maximum in situ stress values are up to $25-30 \mathrm{MPa}$, and the average value of $\sigma_{1} / \sigma_{3}$ is approximately 3.0 (here $\sigma_{1}$ represents the maximum principal stress, and $\sigma_{3}$ represents the minimum principal stress). The maximum principal stress is from $20 \mathrm{MPa}$ to $40 \mathrm{MPa}$. Small-scale fractured zones have been developed in the interfaces of different rock masses. The in situ rock masses exhibit nonhomogeneous weathering and the soft rock zones, fractured zones, and faults are randomly distributed. Therefore, rockbursts and collapses are liable to occur in the process of excavations of the underground caverns. Figure 9 shows the planar graph of the mountain in the Ertan hydropower station.

To better numerically simulate the in situ stress field of the Ertan hydropower station, two lateral pressure coefficients, 1.5 and 2.5, are both considered. According to the in situ geological conditions, four gradually changed weathering zones have been taken into account in the slope surface as shown in Figure 9. The physicomechanical parameters of the surrounding rock mass and four weathering zones are shown in Table 2. Meanwhile, according to the in situ stress measurement results, the directions of the maximum and minimum principal stresses and in situ stress distribution are shown in Figure 10. Since there are more in situ stress measuring points in the left bank, the in situ stress distribution principle can be analyzed. In Figure 10(b), three stress zones have been defined according to the measuring results: stress unloading zone, peak stress zone, and stress stability zone, which are in 


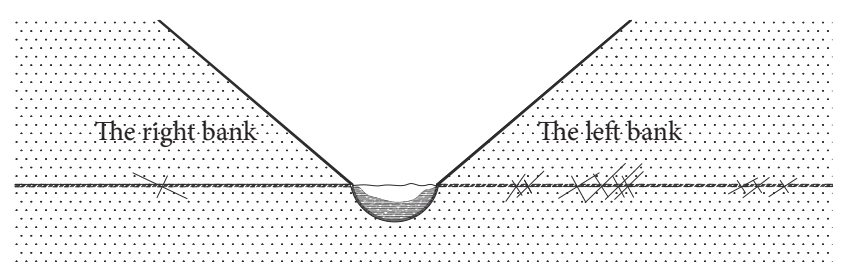

(a)

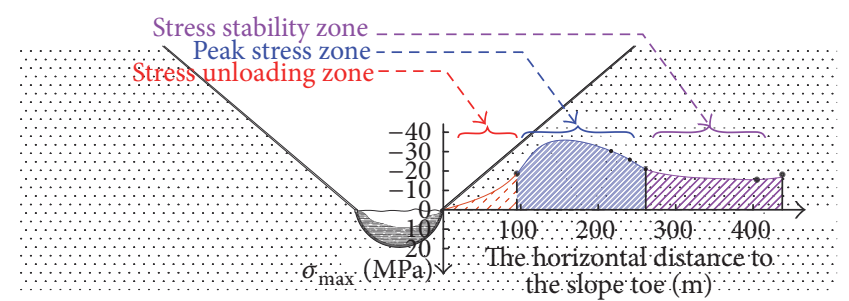

(b)

Figure 10: Directions of the maximum and minimum principal stresses and in situ stress distributions in field measurement: (a) directions of the maximum and minimum principal stresses; (b) in situ stress distribution in the mountain.

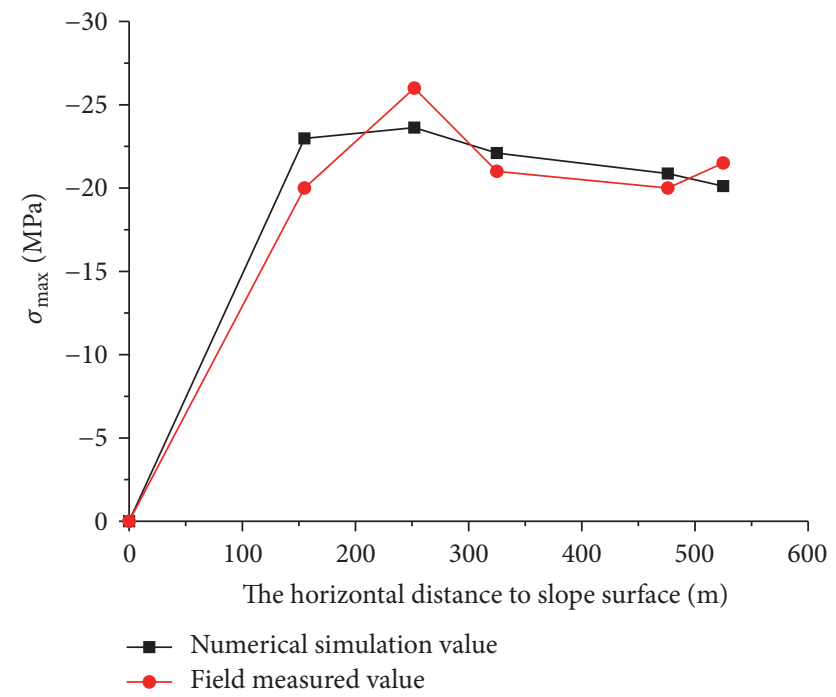

FIGURE 11: Comparative curves of in situ stress values between field measurement and numerical simulation.

good agreement with the numerical simulation results. It is also found that the numerical simulation results when the lateral pressure coefficient is equal to 2.5 are more relevant to those in situ stress measurement results. Figure 11 shows the comparative curves of in situ stress values between field measurement and numerical simulation. It further illustrates that the in situ stress is not just determined by the gravity of the overburden depth, and the horizontal tectonic stress also involves in the in situ stress distribution in the mountains. Due to the complicated in situ stress field, the phenomena of disk-shaped fractures of cores and of rockburst occurred several times during excavations of the underground cavern in the left bank.

\section{Impact of In Situ Stress Distribution Characteristics on Jointed Surrounding Rock Mass Stability of an Underground Cavern: A Case Study}

During the construction of underground projects, jointed rock mass is a frequently encountered and complicated rock mass. The distributions and characteristics of joints have strong influences on the surrounding rock mass stability of underground caverns. In this section, a case study on the jointed surrounding rock mass of the underground caverns in a hydropower station, which is located in Sichuan Province, China.

4.1. Equivalent Physicomechanical Parameters of Jointed Rock Mass. According to engineering investigations and statistical analysis, the distribution principles of the characteristic parameters for the jointed rock mass have been obtained. The joint network consists of a number of randomly distributed joints. Initially, the Monte-Carlo method is employed to generate the random joint network in the simulated specimen [28]. In the same random specimen, Gaussian normal distribution is employed to conduct multiple random assignments for physicomechanical parameters of elements. The generated stochastic joint network and local grids are shown in Figure 12. In the numerical simulation, the variation coefficient $(\nu)$ is defined as the ratio of the expectation value $(\mu)$ to the variance $(S)$ to describe the dispersion degree of Gaussian normal distribution. It can be expressed as follows:

$$
v=\frac{S}{\mu} .
$$

The above generated numerical specimen has been calculated and the size of Representative Elementary Volume (REV) has been obtained. Meanwhile, the numerical specimen has also been calculated under quasi-three-dimensional compressive loading tests with different confining stresses, and quadratic Mohr's envelope is obtained and shown in Figure 13. Therefore, the equivalent physicomechanical parameters of the jointed rock mass under different stress conditions can be obtained by deriving the equation of Mohr's envelope. The relevant parameters can be expressed as follows:

$$
\begin{aligned}
& \tau=C+k \sigma \\
& k=\tan \varphi=\frac{d \tau}{d \sigma}=\frac{a}{2 \sqrt{\tau+a \sigma}} \\
& C=\sqrt{\tau+a \sigma}-\frac{a \sigma}{2 \sqrt{\tau+a \sigma}},
\end{aligned}
$$

where $\tau$ is the tensile strength of the rock mass; $C$ is the cohesion of the rock mass; $k$ represents the slope of the 
TABLE 3: Physicomechanical parameters of intact rock mass and precast fissure.

\begin{tabular}{|c|c|c|c|c|c|c|}
\hline \multirow{2}{*}{ Rock type } & \multirow{2}{*}{$\begin{array}{l}\text { Density } \\
\left(\mathrm{g} / \mathrm{cm}^{3}\right)\end{array}$} & \multirow{2}{*}{ Elastic modulus (GPa) } & \multirow{2}{*}{ Poisson's ratio } & \multicolumn{2}{|c|}{ Shear strength } & \multirow{2}{*}{ Tensile strength $(\mathrm{MPa})$} \\
\hline & & & & Friction angle $\left({ }^{\circ}\right)$ & Cohesion $(\mathrm{MPa})$ & \\
\hline Intact rock & 2,610 & 5.9 & 0.2 & 55 & 3 & 7.5 \\
\hline Rock joint & 2,000 & 0.057 & 0.25 & 26 & 0.05 & 0 \\
\hline
\end{tabular}

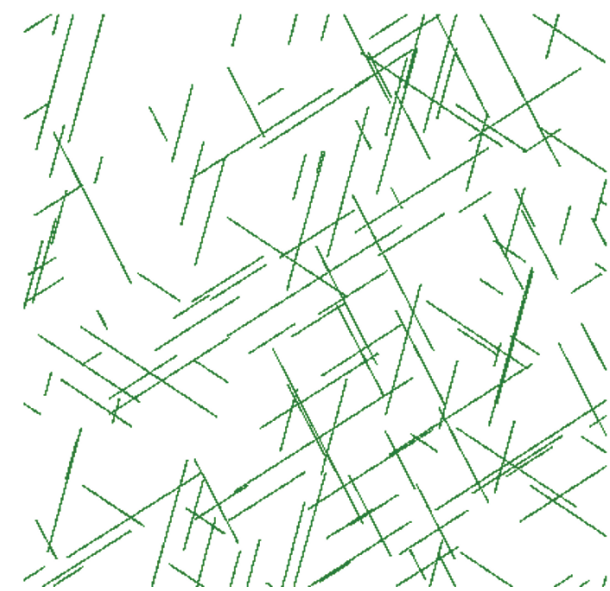

(a)

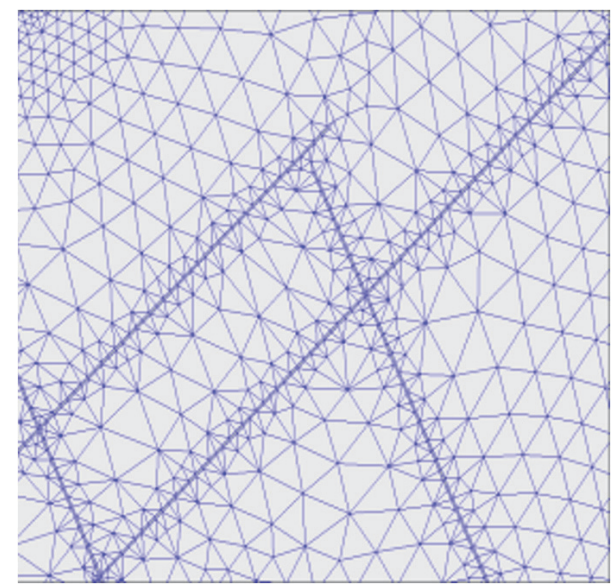

(b)

FIGURE 12: A stochastic joint network and local grids.

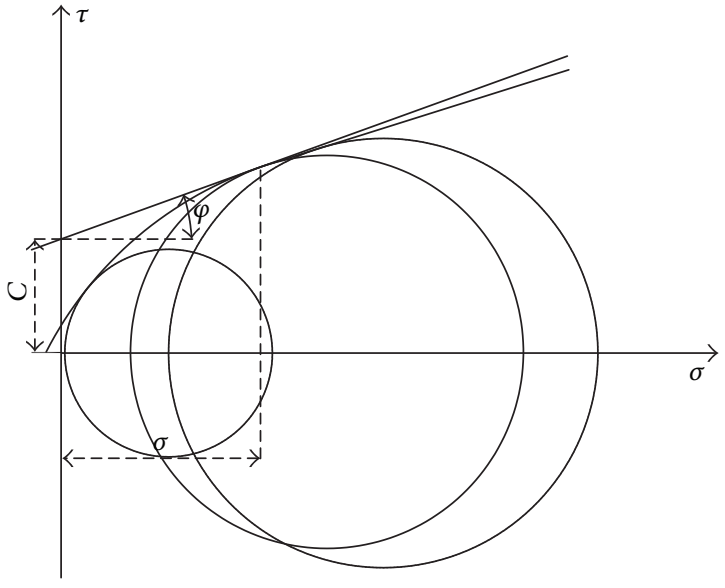

FIGURE 13: Mohr's envelope in the form of quadratic parabola.

tangent line; $\varphi$ is the inner friction angle; $a$ is a fitting parameter.

According to the calculations, expectation values of the physicomechanical parameters of the rock specimen are shown in Table 3.

After derivation calculus to the analytic expression of quadratic Mohr's envelope, the expressions of the cohesion and the friction angle can be obtained as follows:

$$
\begin{aligned}
& C=\sqrt{2.4265 \sigma+0.6063}-\frac{2.4265 \sigma}{2 \sqrt{2.4265 \sigma+0.6063}} \\
& \varphi=\arctan \frac{2.4265 \sigma}{2 \sqrt{2.4265 \sigma+0.6063}} .
\end{aligned}
$$

4.2. A Case Study on the Surrounding Rock Mass Stability of an Underground Cavern. In this part, a $45^{\circ}$ slope is selected as the research object. The surrounding rock mass stability of an underground cavern is numerically studied under the conditions of its different locations in the slope. The height and width of the cavern are $50 \mathrm{~m}$ and $20 \mathrm{~m}$. According to the complex distribution principles of in situ stress near the slope surface, three schemes have been considered with different horizontal distances from the slope toe to the underground cavern as shown in Figure 1. The underground caverns in the three schemes are excavated by four steps. In the numerical simulations, the relevant physicomechanical parameters are shown in Table 3.

4.2.1. Surrounding Rock Mass Stability Analysis Only considering Gravity Stress. Firstly, the three schemes only considering the gravity stress have been numerically simulated. The plastic zones in the three schemes are shown in Figure 14. The numerical simulation results show that the plastic volumes near the underground cavern of the three schemes are $5,179 \mathrm{~m}^{3}, 1,559 \mathrm{~m}^{3}$ and $1,450 \mathrm{~m}^{3}$, respectively. It indicates that the plastic volume would become larger when the horizontal distance between the underground cavern and the slope surface is becoming closer, and the location of the underground cavern in scheme I is extremely unfavorable to the surrounding rock mass stability. Meantime, it also illustrates that the most frequently used method using the direct overburden depth to calculate the vertical in situ stress is unreasonable near the slope surface.

4.2.2. Surrounding Rock Mass Stability Analysis When $k_{0}=$ 1.5. Next, three schemes when the lateral pressure coefficient 


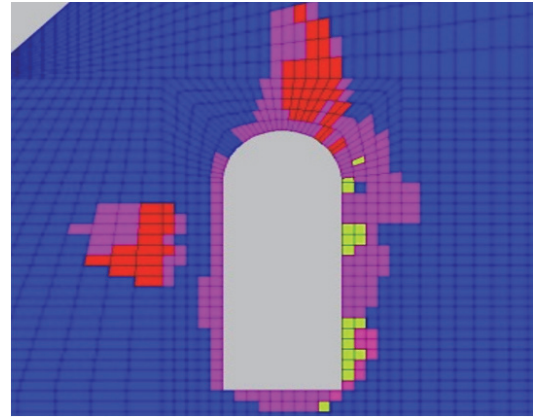

(a)

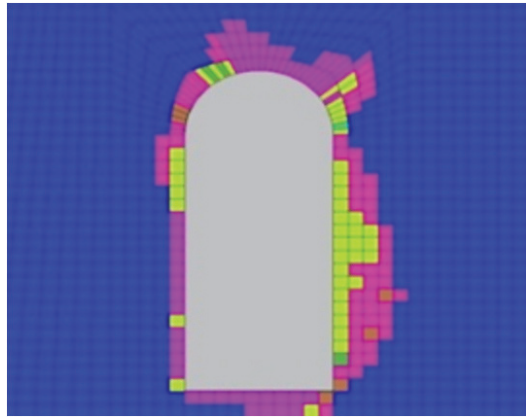

(b)

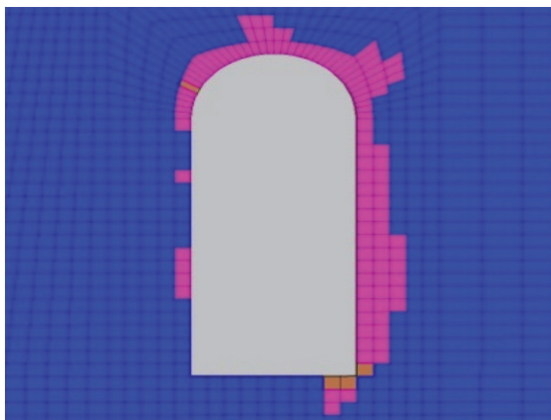

(c)

FIGURE 14: Plastic zones in the three schemes only considering gravity stress: (a) scheme I; (b) scheme II; (c) scheme III.

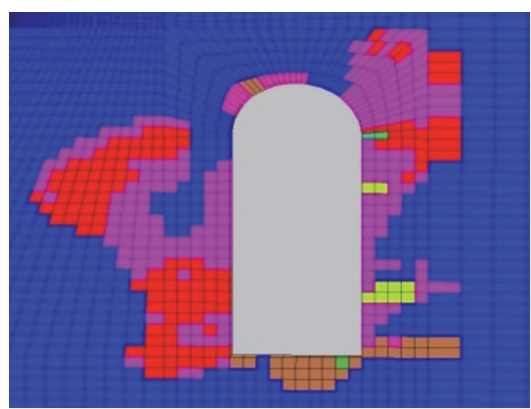

(a)

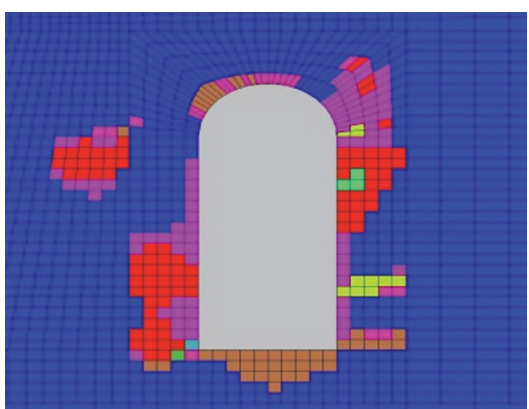

(b)

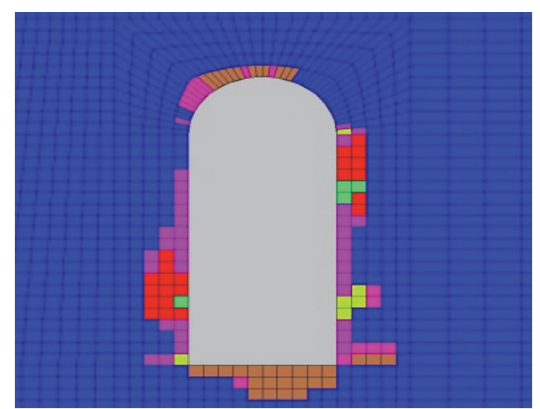

(c)

Figure 15: Plastic zones in the three schemes when the lateral pressure coefficient is equal to 1.5: (a) scheme I; (b) scheme II; (c) scheme III.

is equal to 1.5 have been numerically simulated. The plastic zones in the three schemes are shown in Figure 15. The numerical simulation results show that the plastic volumes near the underground cavern of the three schemes are $8,163 \mathrm{~m}^{3}, 3,688 \mathrm{~m}^{3}$ and $1,578 \mathrm{~m}^{3}$, respectively, which are much larger than those obtained only considering the gravity stress. It indicates that the plastic volume would become much larger when the horizontal distance between the underground cavern and the slope surface is becoming closer. Meantime, in the same scheme, the plastic zones considering the horizontal tectonic stress are closer to the in situ measured results. It can be concluded that the horizontal tectonic stress has significant influences on the surrounding rock mass stability when the underground cavern is excavated near the slope surface.

\section{Conclusions}

This paper employs the three-dimensional Fast Lagrangian Analysis of Continua (FLAC3D) to numerically study the in situ stress distribution characteristics of the rock mass and the surrounding rock mass stability of an underground cavern near a hillslope surface. During the numerical simulations, three different slope angles $\left(30^{\circ}, 45^{\circ}\right.$, and $\left.60^{\circ}\right)$ and different lateral pressure coefficients have been considered. The following conclusions have been drawn:

(1) At the same elevation in the mountain slope, the in situ stress values are much greater than the predicted values according to the vertical overburden depth, especially within $100 \mathrm{~m}$ from the slope surface. With the increasing of the horizontal distance to the slope surface, the vertical in situ stress would be gradually close to the vertical gravity stress. Meantime, the slope angle also has a strong influence on the vertical in situ stress, and the numerical result of the vertical in situ stress is the largest at the slope angle of $60^{\circ}$. Therefore, the determination of the vertical in situ stress should simultaneously consider the influences of the slope angle and the horizontal distance to the slope surface.

(2) In the mountain slope, the additional horizontal tectonic in situ stress cannot be neglected, especially near the slope toe and slope surface. In these areas, the horizontal tectonic stresses are always larger than the vertical in situ stress.

(3) An actual engineering project, the slope of the Ertan hydropower station, is selected to verify the distribution principles of the in situ stress near the slope surface. In the numerical simulations, different lateral pressure coefficients have been considered. Compared with the in situ measured results, numerical results when the lateral coefficient is equal to 2.5 are in good agreement with the real in situ stress values.

(4) In the location selection of the underground cavern near the slope, it is quite unfavorable to be located within $200 \mathrm{~m}$ horizontally to the slope surface as 
complex in situ stress distributions exhibit in these areas. The numerical simulation results under three schemes show that the plastic volume around the underground cavern would become much larger when the horizontal distance between the underground cavern and the slope surface is becoming closer. It can be concluded that the horizontal tectonic stress has significant influences on the surrounding rock mass stability when the underground cavern is excavated near the slope surface.

\section{Competing Interests}

The authors of paper declare that there are no competing interests regarding the publication of this paper. The authors do not have a direct financial relation with the commercial identity that might lead to a conflict of interests for any of the authors.

\section{Acknowledgments}

The work was supported by the National Science and Technology Support Program of China (2015BAB07B05), the Natural Science Foundation of Shandong Province (ZR2016EEQ01), and the Fundamental Research Funds of Shandong University (2016JC007).

\section{References}

[1] H. H. Lai, "China's western development program: its rationale, implementation, and prospects," Modern China, vol. 28, no. 4, pp. 432-466, 2002.

[2] Y. Shang, H.-D. Park, Y. Shi, G. Yuan, and Y. Sun, "Some large values of in-situ stress and related engineering geological problems in China," Geosciences Journal, vol. 14, no. 2, pp. 135$153,2010$.

[3] Y. Li, Y. Guo, W. Zhu, S. Li, and H. Zhou, "A modified initial in-situ Stress Inversion Method based on FLAC3D with an engineering application," Open Geosciences, vol. 7, no. 1, pp. 824835, 2015.

[4] Z. Weishen, L. Yong, L. Shucai, W. Shugang, and Z. Qianbing, "Quasi-three-dimensional physical model tests on a cavern complex under high in-situ stresses," International Journal of Rock Mechanics and Mining Sciences, vol. 48, no. 2, pp. 199-209, 2011.

[5] C. Q. Zhang, X.-T. Feng, H. Zhou, S. L. Qiu, and W. P. $\mathrm{Wu}$, "Rockmass damage development following two extremely intense rockbursts in deep tunnels at Jinping II hydropower station, southwestern China," Bulletin of Engineering Geology and the Environment, vol. 72, no. 2, pp. 237-247, 2013.

[6] Y. Li, H. Zhou, W. Zhu, S. Li, and J. Liu, "Numerical investigations on slope stability using an elasto-brittle model considering fissure water pressure," Arabian Journal of Geosciences, vol. 8, no. 12, pp. 10277-10288, 2015.

[7] Y. Li, H. Zhou, W. Zhu, S. Li, and J. Liu, "Numerical study on crack propagation in brittle jointed rock mass influenced by fracture water pressure," Materials, vol. 8, no. 6, pp. 3364-3376, 2015.

[8] Y. Li, H. Zhou, L. Zhang, W. Zhu, S. Li, and J. Liu, "Experimental and numerical investigations on mechanical property and reinforcement effect of bolted jointed rock mass," Construction and Building Materials, vol. 126, pp. 843-856, 2016.

[9] S. Huang, X. Ding, C. Liao, A. Wu, and J. Yin, "Initial 3D geostress field recognition of high geostress field at deep valley region and considerations on underground powerhouse layout," Chinese Journal of Rock Mechanics and Engineering, vol. 33, no. 11, pp. 2210-2224, 2014 (Chinese).

[10] Y. Liang, The study of in situ stress and rock slope stability analysis in deep-incised valley [Ph.D. thesis], Southwest Jiaotong University, Chengdu, China, 2009 (Chinese).

[11] D. F. McTigue and C. C. Mei, "Gravity-induced stresses near axisymmetric topography of small slope," International Journal for Numerical and Analytical Methods in Geomechanics, vol. 11, no. 3, pp. 257-268, 1987.

[12] H. Winter, S. Adelhardt, A. Jerak, and H. Küchenhoff, "Characterization of cataclastic shear-zones of the KTB deep drill hole by regression analysis of drill cuttings data," Geophysical Journal International, vol. 150, no. 1, pp. 1-9, 2002.

[13] F. Li, J.-A. Wang, and J. C. Brigham, "Inverse calculation of insitustress in rock mass using the surrogate-model accelerated random search algorithm," Computers and Geotechnics, vol. 61, pp. 24-32, 2014.

[14] Y. Nagano, W. Lin, and K. Yamamoto, "In-situ stress analysis using the anelastic strain recovery (ASR) method at the first offshore gas production test site in the eastern Nankai Trough, Japan," Marine and Petroleum Geology, vol. 66, pp. 418-424, 2015.

[15] T. Wang, X. Q. Zhou, S. B. Tian, and H. C. Zhu, "Numerical simulation method for rock natural stress field of a valley and its application based on orthogonal experiments," Rock and Soil Mechanics, vol. 24, no. 5, pp. 831-835, 2003 (Chinese with English abstract).

[16] M.-W. Guo, C.-G. Li, S.-L. Wang, and G.-B. Luan, "Study on inverse analysis of 3-D initial geostress field with optimized displacement boundaries," Yantu Lixue/Rock and Soil Mechanics, vol. 29, no. 5, pp. 1269-1274, 2008.

[17] F.-B. Yuan, J. Liu, P.-J. Li, L.-P. Qiao, and P. Li, "Back analysis and multiple-factor influencing mechanism of high geostress field for river valley region of Laxiwa Hydropower Engineering," Rock and Soil Mechanics, vol. 28, no. 4, pp. 836-842, 2007.

[18] Z. Xu, T.-B. Li, L.-B. Meng, Z.-Y. Xu, and G.-Q. Chen, “Zhegu Mountain tunnel ground stress inversion model and three dimensional ground stress," Journal of Chengdu University of Technology (Science and Technology Edition), vol. 41, no. 2, pp. 243-250, 2014

[19] D.-J. Yu, W.-S. Zhu, M. Yong et al., "Initial geostress field characters in mountain with different slopes and its influence on underground projects," Yantu Lixue/Rock and Soil Mechanics, vol. 32, no. 1, pp. 609-613, 2011.

[20] Y. Li, W. Zhu, J. Fu, Y. Guo, and Y. Qi, “A damage rheology model applied to analysis of splitting failure in underground caverns of Jinping I hydropower station," International Journal of Rock Mechanics and Mining Sciences, vol. 71, pp. 224-234, 2014.

[21] Y. Li, H. Zhou, W. Zhu, S. Li, and J. Liu, "Experimental and numerical investigations on the shear behavior of a jointed rock mass," Geosciences Journal, vol. 20, no. 3, pp. 371-379, 2016.

[22] K. Hayashi and B. C. Haimson, "Characteristics of shut-in curves in hydraulic fracturing stress measurements and determination of in situ minimum compressive stress," Journal of Geophysical Research, vol. 96, no. 11, pp. 18311-18321, 1991.

[23] X. G. Zhao, J. Wang, X. H. Qin et al., "In-situ stress measurements and regional stress field assessment in the Xinjiang 
candidate area for China's HLW disposal," Engineering Geology, vol. 197, pp. 42-56, 2015.

[24] M. H. Talebi, S. Heidari, M. Moosavi, and M. Rahimi, "In situ stress measurements of two hydropower projects in Iran by hydraulic fracturing method," Arabian Journal of Geosciences, vol. 8, no. 9, pp. 7073-7085, 2014.

[25] M. Khoiri, C.-Y. Ou, and F.-C. Teng, "A comprehensive evaluation of strength and modulus parameters of a gravelly cobble deposit for deep excavation analysis," Engineering Geology, vol. 174, no. 8, pp. 61-72, 2014.

[26] S. Zhang and S. Yin, "Determination of horizontal in-situ stresses and natural fracture properties from wellbore deformation," International Journal of Oil, Gas and Coal Technology, vol. 7, no. 1, pp. 1-28, 2014.

[27] W. S. Zhu, X. J. Li, Q. B. Zhang et al., "A study on sidewall displacement prediction and stability evaluations for large underground power station caverns," International Journal of Rock Mechanics and Mining Sciences, vol. 47, no. 7, pp. 10551062, 2010.

[28] J. Zheng, J. Deng, G. Zhang, and X. Yang, "Validation of monte carlo simulation for discontinuity locations in space," Computers and Geotechnics, vol. 67, pp. 103-109, 2015. 


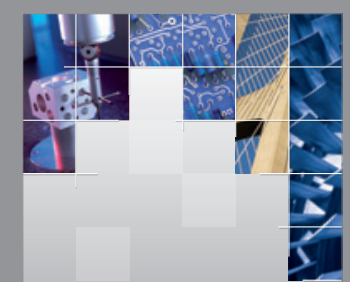

\section{Enfincering}
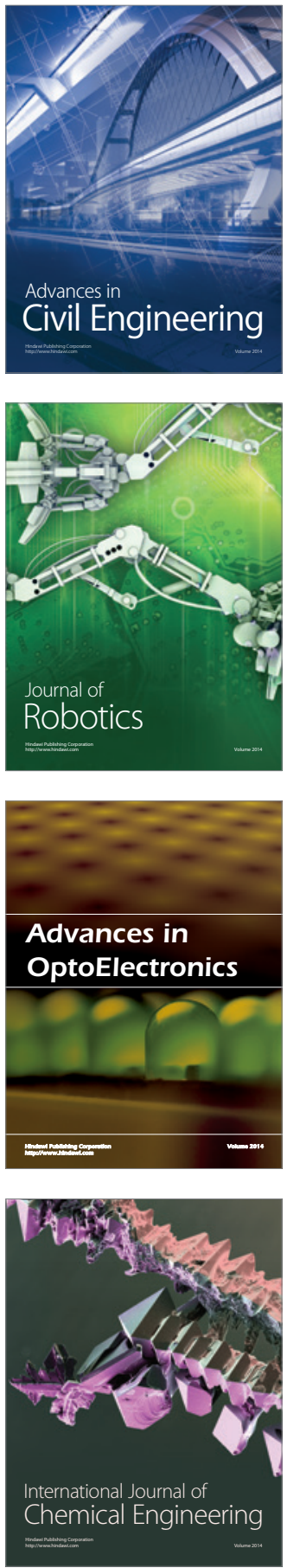

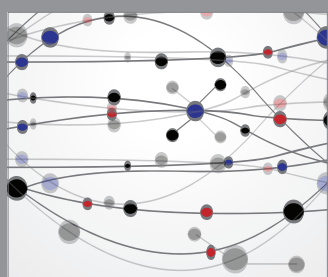

The Scientific World Journal

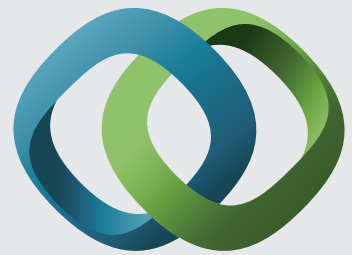

\section{Hindawi}

Submit your manuscripts at

https://www.hindawi.com
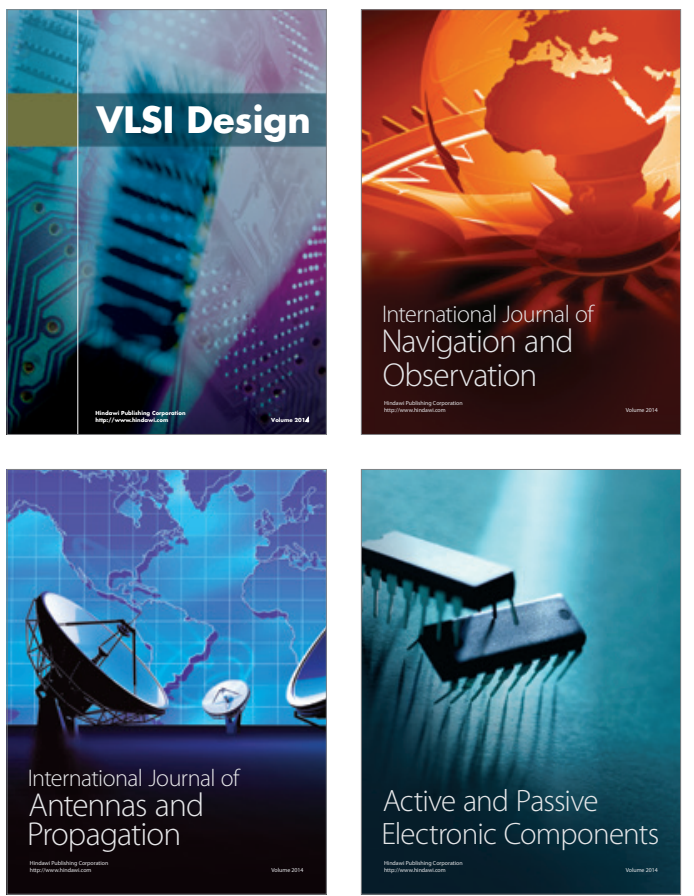
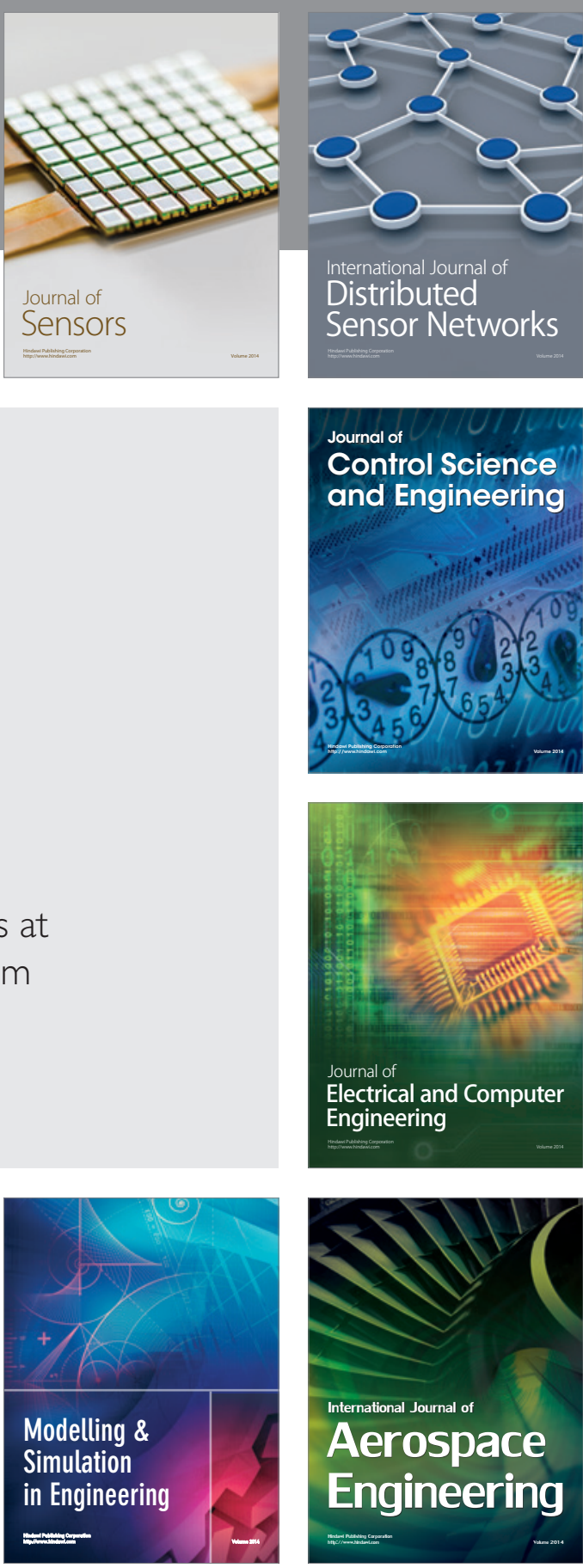

International Journal of

Distributed

Sensor Networks

$-$

Joumal of

Control Science

and Engineering
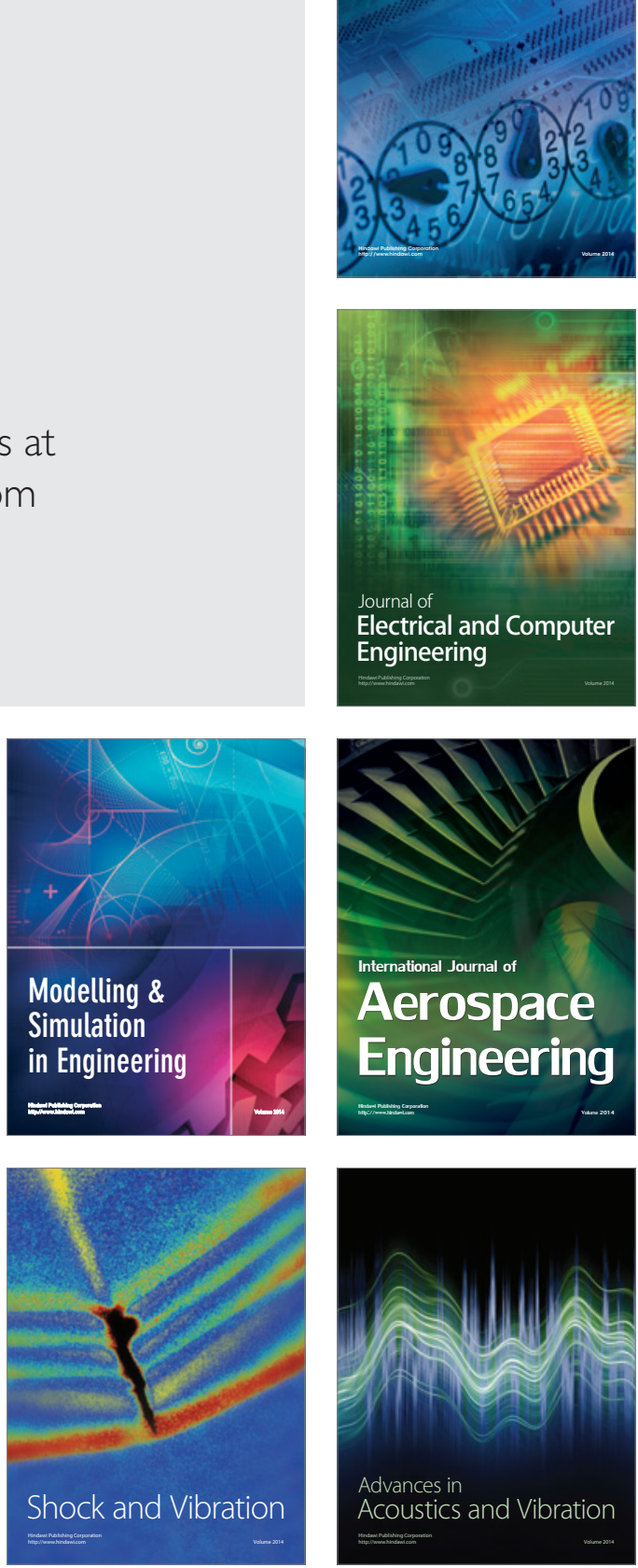